\title{
PERCEPÇÃO DE COMPETÊNCIAS PROFISSIONAIS DE INSTRUTORES DE ATIVIDADES DE AVENTURA NA NATUREZA ATUANTES EM FLORIANÓPOLIS/SC
}

\author{
VIEWS ON PROFESSIONAL COMPETENCIES BY NATURE ADVENTURE ACTIVITIES \\ INSTRUCTORS IN FLORIANÓPOLIS, BRAZIL
}

PERCEPCIÓN DE COMPETENCIAS PROFESIONALES DE INSTRUCTORES DE
ACTIVIDADES DE AVENTURA EN LA NATURALEZA QUE ACTÚAN EN FLORIANÓPOLIS (SC)

Jamille Machado Vaz ${ }^{*}$, Aureo José Amaral Junior*, Priscila Mari dos Santos Correia**, Miraíra Noal Manfroi**, Juliana de Paula Figueiredo**, Alcyane Marinho*

Palavras chave: Percepção.

Competência profissional.

Esportes.

Natureza.

Keywords:

Perception.

Professional

Competence.

Sports.

Nature.

Palabras clave:

Percepción.

Competencia

Profesional.

Deportes.

Naturaleza.
Resumo: Este estudo tem como objetivo analisar a percepcão de competências de instrutores de atividades de aventura na natureza atuantes em Florianópolis/SC. Realizou-se uma pesquisa descritivo-exploratória e quantitativa. Participaram 22 instrutores (18 do sexo masculino e quatro do feminino), com idade média de $39,5 \pm 12,1$ anos. Utilizou-se um questionário validado para este estudo, contendo 27 perguntas baseadas no modelo de competência profissional de Cheetham e Chivers $(1996,1998)$ e na norma 15285 da Associação Brasileira de Normas Técnicas (2005) sobre as competências necessárias aos instrutores. Para analisar os dados, aplicou-se a estatística descritiva. A maioria dos instrutores percebe dominar totalmente as competências cognitivas, funcionais, sociais, éticas e fatores relacionados (metacompetências, personalidade, reflexão, avaliação, empreendedorismo). Contudo, em todas há pelo menos um instrutor que percebe dominá-las parcialmente e há um que percebe não dominar duas competências funcionais relativas à segurança dos participantes. Um instrutor também acredita não dominar a capacidade de empreender.

\begin{abstract}
This study analyzes nature adventure activities instructors' views on competences of in the city of Florianópolis, Brazil. Descriptive-exploratory and quantitative research was carried out, including 22 instructors (18 males and four females) with a mean age of $39.5 \pm 12.1$ years. The study used a validated questionnaire with 27 items based on the model of professional competence of Cheetham and Chivers $(1996,1998)$ and on Standard 15285 of the Brazilian Association of Technical Standards (2005) on instructors' skills needs. Data were analyzed through descriptive statistics. Most instructors think they fully master cognitive, functional, social, ethical and related factors (meta-competencies, personality, reflection, evaluation, entrepreneurship). However, according to instructors themselves, for each of those competencies one instructor masters them only partially and one masters two functional skills on participants' safety. One instructor also believes that he or she does not master the entrepreneurship skill.
\end{abstract}

Resumen: Este estudio tiene como objetivo analizar la percepción de competencias de instructores de actividades de aventura en la naturaleza que actúan en Florianópolis (SC). Se realizó una investigación descriptivo-exploratoria y cuantitativa. Participaron 22 instructores (18 del sexo masculino y cuatro del femenino) con edad media de 39,5 $\pm 12,1$ años. Se utilizó un cuestionario validado para este estudio, con 27 preguntas basadas en el modelo de competencia profesional de Cheetham y Chivers $(1996,1998)$ y en la norma 15285 de la Asociación Brasileña de Normas Técnicas (2005) sobre competencias necesarias para instructores. Para analizar los datos, se aplicó la estadística descriptiva. La mayoría de los instructores cree que domina totalmente las competencias cognitivas, funcionales, sociales, éticas y factores relacionados (metacompetencias, personalidad, reflexión, evaluación, emprendedurismo). Sin embargo, en todas hay al menos un instructor que cree dominarlas parcialmente y hay uno que no cree dominar dos competencias funcionales relacionadas a la seguridad de los participantes. Un instructor también cree no dominar la capacidad de emprender.
*Universidade do Estado de Santa Catarina (UDESC). Florianópolis, SC Brasil.

E-mail: mile_vaz@hotmail.com

**Universidade Federal de Santa Catarina (UFSC). Florianópolis, SC Brasil.

E-mail: priscilamarisantos@hotmail.com

Recebido em: 10-07-2016 Aprovado em: 12-08-2016

(c) (i) () Licence 


\section{INTRODUÇÃO}

Atualmente, é notável o aumento substancial da procura pela vivência de momentos agradáveis junto à natureza. Nesse contexto, algumas práticas vêm ganhando cada vez mais popularidade entre diferentes segmentos sociais, como no caso das atividades de aventura na natureza ${ }^{1}$. Tais atividades estão sendo entendidas como práticas variadas, manifestadas privilegiadamente no lazer e realizadas na água, na terra, ou no ar, diferenciando-se dos esportes ditos "tradicionais" (futebol, voleibol, handebol, entre outros), principalmente por suas condições de práticas e objetivos, além de necessitarem de equipamentos específicos para sua realização (MARINHO, 2008).

Paixão e Tucher (2010) destacam o surgimento contínuo de novas modalidades relacionadas à aventura, as quais, acompanhadas pelo crescente número de adeptos, tornam este segmento um importante mercado de trabalho, suscitando questionamentos acerca das características da formação e da atuação profissional dos indivíduos que trabalham como instrutores ${ }^{2}$ dessas atividades. Os autores explicam que as diferentes modalidades relacionadas à aventura são imbuídas de riscos para os praticantes (como quedas, colisões, fraturas, afogamentos, dentre outros), os quais devem ser adequadamente controlados por instrutores competentes, a fim de assegurar a integridade física e emocional do praticante.

No Reino Unido há o National Governing Body, órgão nacional que contribui com a formação de pessoas que desejam trabalhar com atividades de aventura na natureza, principalmente com montanhismo, escalada, canoagem, orientação, entre outras. Há um número significativo de profissionais que atuam com essas atividades no Reino Unido, capacitados exclusivamente por meio deste sistema, existindo também um incentivo às mulheres para se capacitarem e trabalharem neste ramo. Além da formação, esse órgão oferece prêmios como forma de incentivo à capacitação, demonstrando a organização deste país acerca do segmento aventura (HIGINS; HUMBERSTONE, 1999).

Em contrapartida, no Brasil, observa-se a inexistência de formação oficial específica para o profissional que trabalha como instrutor de atividades de aventura na natureza. Contudo, é comum alguns desses instrutores terem formação inicial em Educação Física, visto que, em função da vinculação histórica dessa área do conhecimento com o esporte, as discussões e as responsabilidades em abordar a temática geralmente recaem sobre ela (PAIXÃO; TUCHER, 2010), sendo possível verificar, em algumas instituições de ensino superior, a existência de disciplinas específicas sobre o assunto na matriz curricular do curso de graduação em Educação Física (INÁCIO; MORAES; SILVEIRA, 2013; SANTOS et al., 2015; MARINHO et al., 2016).

\footnotetext{
1 Este trabalho não contou com apoio financeiro de nenhuma natureza para sua realização.

É pertinente ressaltar que o conceito de aventura é dinâmico, apresentando diferenças significativas quando considerados fatos e/ou momentos históricos específicos. Nessa perspectiva, o termo "aventura" vem sendo associado a diferentes palavras para retratar suas práticas, tais como: esportes de aventura (PAIXÃO; TUCHER, 2010; PAIXÃO et al., 2011), atividades de turismo de aventura (ASSOCIAÇÃO BRASILEIRA DE NORMAS TÉCNICAS, 2005), esportes e atividades de lazer na natureza (ARAÚJO, 2012), práticas corporais de aventura (BRASIL, 2016); práticas corporais de aventura na natureza (INÁCIO; MORAES; SILVEIRA, 2013; INÁCIO et al., 2016), atividades de aventura (AURICCHIO, 2013), atividades físicas de aventura na natureza (BETRÁN; BETRÁN, 2006; TAHARA; CARNICELLI FILHO, 2009), atividades de aventura na natureza (MARINHO, 2004, 2008; CHAO et al., 2015; SANTOS et al., 2015), dentre outros que evidenciam a complexidade do fenômeno e as opções acadêmicas, políticas e epistemológicas dos estudiosos do assunto. Contudo, os autores deste estudo adotam o termo "atividades de aventura na natureza", sem desconsiderar todas as práticas corporais que envolvem o movimento humano neste segmento, incluindo aquelas que se caracterizam como atividade física, esporte ou outros.

2 Assim como ocorre com as terminologias utilizadas para se referir às atividades de aventura na natureza, as expressões para designar os profissionais que atuam com essas atividades são variadas, tais como: instrutor (PAIXÃO et al., 2011; PAIXÃO; TUCHER, 2010), condutor (ASSOCIAÇÃO BRASILEIRA DE NORMAS TÉCNICAS, 2005; CHAO et al., 2015), guia (SCHWARTZ; CARNICELLI FILHO, 2006; TAHARA; CARNICELLI FILHO, 2009), profissional de atividades de aventura (ARAÚJO, 2012; AURICCHIO, 2013). Os autores do presente estudo, entretanto, acreditam que 0 termo "instrutor" se aproxime mais dos aspectos educativos que envolvem a intervenção profissional com as atividades mencionadas, sendo, por isso, elencado para este texto.
} 
Embora a inclusão das atividades de aventura na natureza nos currículos dos cursos de formação inicial em Educação Física ainda se configure como uma lacuna a ser preenchida, considerando que a maioria das instituições federais de ensino superior ainda não aborda 0 tema, acredita-se na importância deste conteúdo para a área e advoga-se para a sua ampliação nos cursos de formação inicial e continuada, bem como para sua inserção no âmbito da Educação Física Escolar (INÁCIO; MORAES; SILVEIRA, 2013). Acredita-se que a Educação Física, também, valendo-se da experiência na natureza, pode potencializar estratégias de ação para desenvolver, nos alunos, habilidades motoras, capacidades físicas e, até mesmo, fundamentos esportivos específicos. Dessa forma, as atividades de aventura na natureza podem ser utilizadas para atingir uma variedade de objetivos educacionais, oportunizando diferentes níveis de desenvolvimento: coletivo (habilidades cooperativas e de comunicação), pessoal (autoestima), cognitivo (tomadas de decisão e resolução de problemas), físico (aptidão e desenvolvimento de habilidades motoras), inclusive, podendo apenas serem utilizadas como atividades de lazer, com fim em si mesmas (MARINHO, 2004).

Nessa perspectiva, é pertinente ressaltar a recente inclusão do conteúdo "práticas corporais de aventura" no componente curricular Educação Física, no contexto do documento referente à Base Nacional Comum Curricular para a Educação Básica, a qual pretende orientar a elaboração curricular das escolas públicas e privadas de todo o país, por meio do estabelecimento de objetivos de aprendizagem e desenvolvimento para cada etapa de escolarização, de acordo com os componentes curriculares de cada área do conhecimento (BRASIL, 2016). Esse cenário certamente implicará mudanças na formação inicial e continuada na área da Educação Física, visto que, sem elas, a inserção das práticas corporais de aventura na natureza como conteúdo a ser obrigatoriamente trabalhado na Educação Física Escolar perderia sentido, relevância e significado (INÁCIO et al., 2016).

No cenário atual, entretanto, estudos brasileiros sobre a formação profissional das pessoas que atuam com as atividades de aventura na natureza vêm constatando a existência de maioria sem formação universitária ou com formação em outras áreas que não a Educação Física (ARAÚJO, 2012; AURICCHIO, 2013; SCHWARTZ; CARNICELLI FILHO, 2006). Além disso, os autores desses mesmos estudos apontam que boa parte das pessoas é capacitada para atuar com determinadas atividades a partir de cursos de pouca duração, oferecidos por associações, federações ou confederações esportivas.

Paixão e Tucher (2010) consideram que o instrutor das modalidades envolvendo a aventura, ainda que, de alguma forma, desempenhe um trabalho docente, apresenta formação e competências profissionais difusas, tornando-se premente investigar e discutir a dinâmica estabelecida entre os elementos que constituem a atuação profissional desses indivíduos. Destaca-se, aqui, o elemento referente às competências percebidas por instrutores de atividades de aventura na natureza. Embora historicamente e, conforme cada área do conhecimento, possam ser atribuídos diferentes significados à competência (SORIANO; WINTERSTEIN, 2006), neste estudo, entende-se a competência para além de um conjunto de conhecimentos, habilidades e atitudes, mas como uma dimensão complexa, relacional e imprevisível, influenciada mutuamente pela ação e relacionada com o sucesso profissional (BATISTA; GRAÇA; MATOS, 2007; BATISTA, 2008).

Diferentes modelos de avaliação de competências profissionais vêm sendo propostos na literatura para serem aplicados com variados grupos de profissões. Um desses modelos, 
considerado como de grande completude por abordar distintas perspectivas de competência, podendo ser utilizado com profissionais de distintas áreas do conhecimento (BATISTA, 2008), é o proposto por Cheetham e Chivers $(1996,1998)$. Nos estudos brasileiros, destaca-se a utilização deste modelo na Educação Física (FARIAS, 2010; FARIAS et al., 2012; SANTOS et al., 2015; MARINHO et al., 2016).

O modelo de Cheetham e Chivers $(1996,1998)$ é composto por quatro grupos de competências nucleares, subdivididos em dimensões: 1) conhecimento/competência cognitiva, que contempla cinco dimensões - conhecimento técnico e teórico especializado, conhecimento tácito, conhecimento processual, conhecimento contextual e aplicação do conhecimento; 2) competência funcional, organizada em quatro dimensões - competência específica do ofício, organização e gestão, competência motora e competência básica; 3) competência pessoal e social, sistematizada na dimensão intraprofissional e na dimensão social e vocacional; e 4) valores/competência ética, a qual contempla a ética profissional e a ética pessoal. O modelo também engloba alguns fatores relacionados à competência: hetero e autopercepção de competência; metacompetências/transcompetências (por exemplo: criatividade, comunicação, versatilidade, resolução de problemas); contexto de trabalho e envolvimento do trabalho; personalidade; motivação; e reflexão.

Para além desse modelo, aponta-se a existência, no Brasil, de normas técnicas que elencam as competências mínimas necessárias aos condutores de atividades de turismo de aventura, independentemente da modalidade em que atuam profissionalmente. Por existirem procedimentos comuns aos condutores dessas atividades, a Associação Brasileira de Normas Técnicas (ABNT), em parceria com o Ministério do Turismo, estabeleceu, em 2005, competências transversais aos condutores de atividades de turismo de aventura por meio da NBR $15285^{3}$. As competências dizem respeito ao atendimento e à condução dos participantes; à prestação de um serviço de qualidade; à segurança; e aos cuidados com o ambiente e com as comunidades envolvidas.

Apesar da existência desse documento legal e dos estudos sobre percepção de competências profissionais na área da Educação Física com base no modelo de Cheetham e Chivers $(1996,1998)$, em busca realizada pelos autores da presente pesquisa não foram identificadas, no cenário nacional, investigações científicas específicas sobre a percepção de competências profissionais de instrutores de atividades de aventura na natureza. Acredita-se que estudos com essa proposta sejam importantes para se refletir sobre quais competências estão sendo efetivamente manifestadas pelos instrutores, a partir de suas percepções, discutindo-as na inter-relação das exigências e demandas desse campo emergente de atuação profissional, que abrange praticantes de diferentes faixas etárias, lugares, formações e com múltiplos interesses (lazer, busca por prazer, vivência de sensações e emoções, procura por desafios, prática de atividade física, etc.). Assim, este estudo tem como objetivo analisar a percepção de competências profissionais de instrutores de atividades de aventura na natureza atuantes em Florianópolis/SC.

\section{METODOLOGIA}

Esta pesquisa foi desenvolvida por meio de uma investigação de campo, com corte transversal, do tipo descritivo-exploratória, com abordagem quantitativa dos dados. De acordo

3 Em 2015, a norma foi atualizada, contudo, a nova versão ainda se encontra em processo de validação para o cenário nacional. 
com Gil (2008), a pesquisa descritiva pretende descrever características de determinada população/fenômeno e/ou estabelecer relações entre variáveis. A pesquisa exploratória, por sua vez, objetiva proporcionar uma visão geral acerca de determinado contexto, desenvolvendo, esclarecendo ou modificando conceitos e ideias sobre ele. Conforme apontam Marconi e Lakatos (2009), é comum a combinação das pesquisas descritiva e exploratória a fim de detalhar ao máximo determinado fenômeno. No que se refere à abordagem quantitativa, o foco recai sobre as quantidades, expressas por meio de dados numéricos levantados a partir de instrumentos de coleta de dados (MARCONI; LAKATOS, 2009).

Participaram desta pesquisa 22 instrutores de atividades de aventura na natureza atuantes em 13 empresas neste ramo em Florianópolis/SC, nas modalidades de surfe $(n=7)$, remo $(n=6)$, stand up paddle $(n=5)$, kitesurf $(n=4)$, windsurf $(n=2)$, mergulho $(n=2)$, natação de travessia $(n=1)$ e voo livre $(n=1)$, sendo 18 do sexo masculino e quatro do sexo feminino, com idade média de 39,5 $\pm 12,1$ anos. Para a seleção dos participantes foram estabelecidos como critérios de inclusão: tempo mínimo de um ano de atuação profissional com atividades de aventura na natureza; e idade mínima de 18 anos. 0 tempo médio de atuação profissional

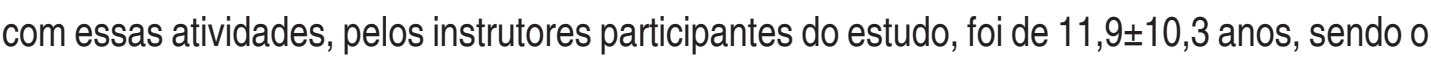
menor tempo de atuação o de um ano e o maior o de 45 anos. Por sua vez, foram determinados como critérios de exclusão: afastamento do contexto de atuação profissional com atividades de aventura na natureza por qualquer motivo, durante o período de coleta de dados; e não saber ler e/ou escrever, impossibilitando responder aos questionamentos do instrumento de coleta de dados utilizado. Importante informar que, dentre os participantes do estudo, nove informaram ter ensino médio completo, enquanto 13 indicaram ter ensino superior completo em Educação Física $(n=5)$, Administração ( $n=2)$, Engenharia de Aquicultura $(n=2)$, Engenharia Sanitária $(n=1)$, Economia $(n=1)$, Ciências Biológicas $(n=1)$, Tecnólogo em Radiologia $(n=1)$. Além disso, 13 profissionais participaram de cursos técnicos específicos de capacitação profissional na área das atividades em que atuam nos últimos cinco anos (de 2010 a 2014).

Apesar do estabelecimento dos critérios de inclusão e de exclusão supramencionados, não foram utilizados procedimentos probabilísticos para a seleção dos participantes deste estudo. Foram convidados a participar todos os profissionais que atenderam aos critérios de inclusão. Ressalta-se que, a princípio, foram identificadas 48 empresas, entretanto, nem todas aceitaram participar do estudo e algumas não atenderam aos telefonemas, não responderam ao e-mail, ou, ainda, estavam fechadas ou fora de temporada, inviabilizando o contato.

As empresas foram identificadas a partir de um levantamento prévio, realizado pelos autores deste estudo, junto aos cadastros da Santa Catarina Turismo S.A. (SANTUR), da Associação Brasileira das Empresas de Ecoturismo e Turismo de Aventura (ABETA) e junto aos sites da Prefeitura de Florianópolis, das confederações, federações e associações das diferentes modalidades contempladas por essas atividades. Essas modalidades, por sua vez, foram consideradas conforme classificação de atividades físicas de aventura na natureza proposta por Betrán e Betrán (2006), que as organiza quanto ao ambiente físico (subdividido em meio, plano e incerteza), ao ambiente pessoal (incluindo a dimensão emocional, sensação e recursos biotecnológicos), às atividades (subdivididas em práticas e grupo de práticas), à valorização ético-ambiental (de modo a caracterizar o nível de impacto ecológico, se é alto, médio ou baixo) e ao ambiente social (referente à implicação prática, se é individual, em grupo com colaboração ou em grupo sem colaboração). 
Como instrumento de coleta de dados foi utilizado um questionário construído e validado especificamente para este estudo, contendo 27 perguntas fechadas. 0 questionário foi elaborado com base no modelo de competência profissional desenvolvido por Cheetham e Chivers $(1996,1998)$ e na norma NBR 15285, publicada pela ABNT em 2005. O Quadro 1, a seguir, apresenta as competências contempladas no questionário validado.

Quadro 1 - Competências avaliadas pelo instrumento de coleta de dados validado para este estudo.

\begin{tabular}{|c|c|c|}
\hline $\begin{array}{l}\text { Competências } \\
\text { avaliadas }\end{array}$ & Dimensões das competências & Fundamentação Teórica \\
\hline \multirow{4}{*}{$\begin{array}{l}\text { Conhecimentos } \\
\text { / competência } \\
\text { cognitiva }\end{array}$} & Conhecimentos teóricos & $\begin{array}{l}\text { Cheetham e Chivers (1998) } \\
\text { e ABNT (2005) }\end{array}$ \\
\hline & Aplicação do conhecimento & \multirow{2}{*}{ Cheetham e Chivers (1998) } \\
\hline & Conhecimento processual & \\
\hline & Capacidade de planejamento & ABNT (2005) \\
\hline \multirow{8}{*}{$\begin{array}{l}\text { Competências } \\
\text { funcionais }\end{array}$} & Competência específica do ofício: utilizar equipamentos & \multirow{3}{*}{$\begin{array}{l}\text { Cheetham e Chivers (1998) } \\
\text { e ABNT (2005) }\end{array}$} \\
\hline & $\begin{array}{l}\text { Competência específica do ofício: condições dos } \\
\text { equipamentos }\end{array}$ & \\
\hline & Competência específica do ofício: instrução & \\
\hline & Organização e gestão - situações inesperadas & $\begin{array}{l}\text { Cheetham e Chivers (1998) } \\
\text { e ABNT (2005) }\end{array}$ \\
\hline & Organização e gestão - necessidades dos participantes & $\begin{array}{l}\text { Cheetham e Chivers (1998) } \\
\text { e ABNT (2005) }\end{array}$ \\
\hline & Segurança - fornecer informações aos participantes & ABNT (2005) \\
\hline & Segurança - gerenciar situações de emergência & ABNT (2005) \\
\hline & Segurança - aplicar técnicas de primeiros socorros & ABNT (2005) \\
\hline \multirow{3}{*}{$\begin{array}{l}\text { Competência pessoal } \\
\text { e social }\end{array}$} & Competências intraprofissionais & Cheetham e Chivers (1998) \\
\hline & Competências sociais e vocacionais: autoconfiança & \multirow{2}{*}{$\begin{array}{l}\text { Cheetham e Chivers (1998) } \\
\text { e ABNT (2005) }\end{array}$} \\
\hline & Competências sociais e vocacionais: empatia & \\
\hline \multirow{5}{*}{$\begin{array}{l}\text { Valores / } \\
\text { competências éticas }\end{array}$} & Ética pessoal & $\begin{array}{l}\text { Cheetham e Chivers (1998) } \\
\text { e ABNT (2005) }\end{array}$ \\
\hline & Ética profissional: código profissional de conduta ética & \multirow{2}{*}{$\begin{array}{l}\text { Cheetham e Chivers (1998) } \\
\text { e ABNT (2005) }\end{array}$} \\
\hline & Ética profissional: atualização & \\
\hline & Sensibilização ambiental & \multirow{2}{*}{ ABNT (2005) } \\
\hline & Comprometimento socioambiental & \\
\hline \multirow{3}{*}{$\begin{array}{l}\text { Fatores relacionados } \\
\text { / metacompetências }\end{array}$} & Liderança & ABNT (2005) \\
\hline & Motivação - Capacidade de incentivar os outros & ABNT (2005) \\
\hline & Criatividade & Cheetham e Chivers (1998) \\
\hline $\begin{array}{l}\text { Fatores relacionados } \\
\text { / personalidade }\end{array}$ & Controlar características pessoais & $\begin{array}{l}\text { Cheetham e Chivers (1998) } \\
\text { e ABNT (2005) }\end{array}$ \\
\hline $\begin{array}{l}\text { Fatores relacionados } \\
\text { / reflexão }\end{array}$ & Reflexão sobre sua atuação & Cheetham e Chivers (1998) \\
\hline $\begin{array}{l}\text { Fatores relacionados } \\
\text { / avaliação }\end{array}$ & Avaliar sua atuação & \multirow{2}{*}{ ABNT (2005) } \\
\hline $\begin{array}{l}\text { Fatores relacionados } \\
\text { / empreendedorismo }\end{array}$ & Identificar novas oportunidades & \\
\hline
\end{tabular}

Fonte: autoria própria (2016). 
A escala de respostas adotada no questionário foi do tipo Likert, sendo que os instrutores deveriam assinalar, para cada competência: " 0 = não domino esta competência"; ou, "1 = domino parcialmente esta competência"; ou, "2 = domino totalmente esta competência".

Para validação deste questionário foram seguidas as instruções de validação de conteúdo e avaliação de clareza de linguagem de instrumentos de coleta, descritas por Dal Pupo, Schutz e Santos (2011) e por Santos e Gheller (2012), cientes dos limites implícitos nessa técnica, mas com rigor científico necessário para tal. 0 questionário foi enviado por e-mail para avaliação de três professores doutores, estudiosos da temática deste estudo, a fim de analisarem a validade do conteúdo e a clareza da linguagem empregada nas questões. Além disso, o instrumento foi enviado para quatro profissionais de atividades de aventura na natureza, atuantes como instrutores dessas atividades em outras cidades brasileiras, a fim de avaliarem a clareza da linguagem das perguntas.

Para cada questão os colaboradores do processo de validação deveriam atribuir uma nota, de zero a dez, avaliando-a, no que se refere ao conteúdo, como "não válida" (notas de zero a quatro); ou, "pouco válida" (notas de cinco a sete); ou, "válida" (notas de oito a dez); e, no que concerne à clareza, como "confusa" (notas de zero a quatro); ou, "pouco clara" (notas de cinco a sete); ou, "clara" (notas de oito a dez). Os avaliadores também poderiam descrever sugestões e/ou fazer comentários sobre cada questão. Após três rodadas de avaliação, realizadas no período de dois meses, o questionário, que tinha inicialmente 35 questões, foi sendo reajustado até ser validado por meio de sua versão final com 27 perguntas, alcançando os índices de 0,91 para validade de conteúdo e 0,91 para clareza de linguagem, na avaliação dos professores doutores; e de 0,95 para clareza de linguagem, na avaliação dos instrutores colaboradores. Conforme Dal Pupo, Schutz e Santos (2011), um instrumento de medida pode ser considerado válido e claro quando seus índices forem maiores ou iguais a 0,8.

Os dados coletados foram analisados por meio da estatística descritiva (frequência simples, média e desvio padrão), utilizando-se o software Microsoft Excel versão 2010. Devese informar, ainda, que este estudo foi aprovado pelo Comitê de Ética em Pesquisas com Seres Humanos da Universidade do Estado de Santa Catarina, sob número do parecer 460.441, de 18/11/2013. Os participantes desta pesquisa assinaram um Termo de Consentimento Livre e Esclarecido em duas vias, sendo uma para eles mesmos e outra para os pesquisadores.

\section{RESULTADOS E DISCUSSÕES}

Preliminarmente, deve-se salientar que a competência profissional tem um vínculo de ordem normativa, na medida em que sempre implica juízos de valor acerca do que é, ou não, apropriado para determinada situação referente a um campo de intervenção profissional (BATISTA; GRAÇA; MATOS, 2007). Nessa perspectiva, a ênfase dada em determinados aspectos relacionados às competências profissionais (conhecimentos, habilidades, aptidões, etc.) depende da relação de construção de identidade, de imagem de si mesmo, de inserção nas relações sociais e do itinerário pessoal ou familiar que o profissional mantém, visto que a competência está muito mais relacionada à subjetividade (SORIANO; WINTERSTEIN, 2006), ou seja, à percepção de cada indivíduo.

Partindo dessas considerações, apresentam-se, na sequência, tabelas contendo as frequências de respostas referentes à percepção de competências pelos instrutores de 
atividades de aventura na natureza investigados. A Tabela 1, a seguir, está centrada nas competências cognitivas. De acordo com Cheetham e Chivers $(1996,1998)$, esse grupo de competências refere-se à posse de conhecimentos relacionados à profissão e à capacidade de utilizá-los de forma eficaz nas atividades laborais. É possível observar que a maioria dos instrutores percebe dominar totalmente essas competências.

Tabela 1 - Percepções de competências cognitivas por instrutores de atividades de aventura na natureza atuantes em Florianópolis/SC ( $\mathrm{n}=22)$.

\begin{tabular}{llcc}
\hline & & \multicolumn{2}{c}{ Percepção de competências } \\
\hline $\begin{array}{l}\text { Competência } \\
\text { nuclear }\end{array}$ & $\begin{array}{l}\text { Dimensões da competência } \\
(\mathbf{f})\end{array}$ & $\begin{array}{c}\text { Domina parcialmente esta } \\
\text { competência (f) }\end{array}$ & $\begin{array}{c}\text { Domina totalmente esta } \\
\text { competência (f) }\end{array}$ \\
\hline \multirow{2}{*}{$\begin{array}{l}\text { Conhecimentos } \\
\text { I Competência } \\
\text { cognitiva }\end{array}$} & Conhecimentos teóricos & 6 & 16 \\
\cline { 2 - 4 } & Aplicação do conhecimento & 3 & 19 \\
\cline { 2 - 4 } & Conhecimento processual & 2 & 20 \\
\cline { 2 - 4 } & Capacidade de planejamento & 4 & 18 \\
\hline
\end{tabular}

f: frequência simples.

Fonte: Autoria própria (2016).

Os conhecimentos teóricos dizem respeito à base de conhecimento formal da profissão (CHEETHAM; CHIVERS, 1996, 1998), sendo geralmente associados aos conhecimentos obtidos durante a formação inicial, às teorias, aos princípios, aos conceitos e à fundamentação técnica e teórica específica de cada área de intervenção (BATISTA, 2008; FARIAS et al., 2012; SANTOS et al., 2012). A capacidade de planejamento, por sua vez, inclui, segundo a Associação Brasileira de Normas Técnicas (2005), a previsão e a organização de todas as tarefas envolvidas na instrução das atividades relacionadas à aventura, abrangendo desde a preparação de itinerários, rotas e medidas de emergência, até as alternativas para lidar com situações imprevistas.

Talvez a percepção de alguns profissionais investigados em dominar parcialmente essas duas competências seja referente à possível relação delas com cursos de capacitação profissional, tanto em nível de graduação, quanto no contexto da formação continuada por meio de eventos, palestras, congressos e iniciativas diversas, as quais ainda parecem não alcançar considerável parte dos profissionais envolvidos em atividades relacionadas à aventura (ARAÚJO, 2012; AURICCHIO, 2013; SCHWARTZ; CARNICELLI FILHO, 2006), dificultando 0 fortalecimento da categoria do profissional que atua nessa área e sua representatividade no contexto social brasileiro (PAIXÃO; TUCHER, 2010). Por outro lado, a recente inserção de conhecimentos teóricos relativos a essas atividades na matriz curricular de cursos de graduação, tais quais os da área da Educação Física, por meio de disciplinas específicas, pode ser uma possibilidade de contribuir para o desenvolvimento desta competência, conforme observado no estudo de Marinho et al. (2016), com 80 estudantes da última fase do curso de Bacharelado em Educação Física de uma universidade pública de Santa Catarina, no qual esta competência foi evidenciada entre aquelas percebidas pelos estudantes em período final de formação.

A aplicação do conhecimento, por sua vez, sublinha a dimensão de racionalidade técnica que inclui a síntese, a transposição e a transferência do conhecimento para a prática; enquanto 0 conhecimento processual abrange as rotinas básicas inseridas na atividade profissional (CHEETHAM; CHIVERS, 1996, 1998), fazendo referência, neste caso, ao domínio das etapas 
de ensino das atividades de aventura na natureza, facilitando o aprendizado do participante. Acredita-se que ambas essas competências pressupõem o domínio de conhecimentos teóricos e técnicos especializados, os quais, se faltam a alguns instrutores, implicam na percepção por partes destes de domínio limitado também na dimensão da aplicação do conhecimento e nas rotinas processuais.

No que se refere às competências funcionais, apresentadas na Tabela 2, também se pode observar que a maioria dos instrutores se percebe totalmente competente neste grupo de competências, as quais dizem respeito à capacidade de executar com eficiência e eficácia uma série de tarefas específicas de cada profissão (CHEETHAM; CHIVERS, 1996, 1998). Quando se aborda, contudo, as competências relativas à segurança dos participantes, há profissionais que acreditam não dominar ou dominar parcialmente o gerenciamento de situações de emergência, assim como a aplicação de técnicas de primeiros socorros.

Tabela 2 - Percepções de competências funcionais por instrutores de atividades de aventura na natureza atuantes em Florianópolis/SC ( $\mathrm{n}=22)$.

\begin{tabular}{lllcc}
\hline & & \multicolumn{3}{c}{ Percepção de competências } \\
\hline $\begin{array}{l}\text { Competência } \\
\text { nuclear }\end{array}$ & Dimensões da competência (f) & $\begin{array}{c}\text { Não domina esta } \\
\text { competência (f) }\end{array}$ & $\begin{array}{c}\text { Domina } \\
\text { parcialmente esta } \\
\text { competência (f) }\end{array}$ & $\begin{array}{c}\text { Domina } \\
\text { totalmente esta } \\
\text { competência (f) }\end{array}$ \\
\hline & $\begin{array}{l}\text { Competência específica do ofício - } \\
\text { utilizar equipamentos }\end{array}$ & 0 & 2 & 20 \\
\cline { 2 - 5 } & $\begin{array}{l}\text { Competência específica do ofício - } \\
\text { condições dos equipamentos }\end{array}$ & 0 & 3 & 19 \\
\hline $\begin{array}{l}\text { Competência específica do ofício } \\
\text { Competência } \\
\text { funcional }\end{array}$ & $\begin{array}{l}\text { - instrução } \\
\begin{array}{l}\text { Organização e gestão - situações } \\
\text { inesperadas }\end{array}\end{array}$ & 0 & 3 & 19 \\
\hline $\begin{array}{l}\text { Organização e gestão - } \\
\text { necessidades dos participantes }\end{array}$ & 0 & 4 & 18 \\
\hline $\begin{array}{l}\text { Segurança - fornecer informações } \\
\text { aos participantes }\end{array}$ & 0 & 4 & 18 \\
\hline $\begin{array}{l}\text { Segurança - gerenciar situações } \\
\text { de emergência }\end{array}$ & $\begin{array}{l}\text { Segurança - aplicar técnicas de } \\
\text { primeiros socorros }\end{array}$ & 1 & 3 & 16 \\
\hline
\end{tabular}

Brown e Fraser (2009), assim como Marinho (2008), ressaltam que o risco constituiu, muitas vezes, uma das fontes de motivação do indivíduo para a prática das atividades de aventura na natureza e se apresenta como um elemento indissociável da aventura. Marinho (2008) ainda destaca que o risco expressa uma probabilidade de que alguma situação aconteça inesperadamente e por determinado momento, podendo acarretar sensações negativas (como medo e incerteza), mas, também, positivas e prazerosas (situações desafiadoras e facilitadoras de novos conhecimentos).

Dessa forma, uma vivência com tais atividades coloca à prova competências e capacidades próprias, nas quais os riscos iminentes precisam ser bem avaliados e controlados, visto que eles podem, de fato, expor o participante à possibilidade de se machucar ou, até 
mesmo, de vir a óbito. Habilidades pessoais, decisões corretas e prudentes, assim como 0 auxílio de aparelhos tecnológicos, contribuem para aumentar o senso de segurança nessas atividades (MARINHO, 2008).

Nesse contexto, é pertinente destacar que alguns instrutores percebem dominar parcialmente a capacidade de utilização de equipamentos necessários às atividades de aventura na natureza, assim como a capacidade de identificação das suas condições de uso. No estudo de Paixão et al. (2011), os 121 instrutores investigados, atuantes em Minas Gerais, demonstraram compreender que a integridade do participante está atrelada ao domínio da técnica, ao manuseio dos equipamentos de aporte e segurança e ao conhecimento da região, no sentido de evitar que os praticantes se coloquem em situações acentuadas de risco.

Por outrolado, Paixão e Tucher (2010) lembram que apenas a utilização de equipamentos sofisticados não é suficiente para impedir incidentes relacionados às modalidades associadas à aventura. Assim, quando a prática dessas modalidades se encontra aliada a procedimentos e estratégias advindos de conhecimentos de uma dada modalidade, há uma tendência a minimizar acidentes. Os autores salientam ainda que, diante de situações imprevistas, os instrutores deveriam ser capazes de decidir e agir antecipadamente, por meio de estratégias a serem utilizadas para superar o obstáculo (risco objetivo) e atingir os objetivos inicialmente traçados no decorrer da atividade.

Todavia, quatro instrutores investigados no presente estudo acreditam ser parcialmente capazes de lidar com ocasiões inesperadas, bem como de adaptar o programa de atividades de aventura na natureza conforme as necessidades dos participantes. Ademais, três instrutores percebem-se parcialmente capazes de instruir os participantes, no sentido de transmitir claramente a esses últimos o conteúdo das atividades de aventura na natureza. Esses resultados fornecem elementos para a reflexão acerca dos tipos de orientação que os praticantes dessas atividades vêm recebendo, por parte dos instrutores, e de suas implicações para a garantia da segurança dos participantes.

Nesse contexto de instrução/orientação, também se fazem presentes as competências pessoais e sociais relativas à adoção de comportamentos adequados que podem ser observados nas situações de trabalho. As competências intraprofissionais referem-se, principalmente, às interações com outros profissionais, incluindo aspectos relacionados à colegialidade; enquanto as competências sociais e vocacionais incluem habilidades interpessoais, como a autoconfiança e a empatia (CHEETHAM; CHIVERS, 1996, 1998). Os resultados referentes a essas competências podem ser visualizados na Tabela 3.

Tabela 3 - Percepções de competências pessoais e sociais por instrutores de atividades de aventura na natureza atuantes em Florianópolis/SC ( $\mathrm{n}=22)$.

\begin{tabular}{|c|c|c|c|}
\hline \multirow[b]{2}{*}{$\begin{array}{l}\text { Competência } \\
\text { nuclear }\end{array}$} & \multirow[b]{2}{*}{ Dimensões da competência (f) } & \multicolumn{2}{|c|}{ Percepção de competências } \\
\hline & & $\begin{array}{l}\text { Domina parcialmente } \\
\text { esta competência (f) }\end{array}$ & $\begin{array}{l}\text { Domina totalmente } \\
\text { esta competência (f) }\end{array}$ \\
\hline \multirow{3}{*}{$\begin{array}{l}\text { Competência } \\
\text { pessoal e social }\end{array}$} & Competências intraprofissionais & 2 & 20 \\
\hline & $\begin{array}{l}\text { Competências sociais e vocacionais - } \\
\text { autoconfiança }\end{array}$ & 2 & 20 \\
\hline & Competências sociais e vocacionais - empatia & 2 & 20 \\
\hline \multicolumn{4}{|c|}{$\begin{array}{l}\text { f: frequência simples. } \\
\text { Fonte: Autoria própria (2016). }\end{array}$} \\
\hline
\end{tabular}


A capacidade de transmitir confiança aos participantes, sabendo como atuar diante das situações diversas durante as atividades e o que dizer aos praticantes, estabelecendo relações a fim de deixá-los confortáveis, é considerada uma das competências esperadas dos profissionais atuantes deste segmento (ASSOCIAÇÃO BRASILEIRA DE NORMAS TÉCNICAS, 2005). A percepção de domínio parcial desta competência por parte de dois instrutores pode estar relacionada ao tempo de experiência com a atividade em que atuam profissionalmente, uma vez que mais experiências prévias com a modalidade favorecem certo domínio das situações e a autoconfiança dos instrutores, conforme verificado no estudo de Schwartz e Carnicelli Filho (2006) com 20 indivíduos atuantes na modalidade de rafting em Brotas (SP). Por sua vez, a percepção de dominar parcialmente a capacidade de empatia e de interações com outros profissionais pode depender das características pessoais de cada instrutor e também do contexto de trabalho facilitar, ou não, as relações com outros instrutores. No estudo de Marinho et al. (2016), embora desenvolvido com estudantes em final de formação na área da Educação Física, os quais poderão atuar profissionalmente ou não com atividades de aventura na natureza, a empatia e a capacidade de manter boas interações com os demais estudantes e com instrutores dessas atividades foram destacadas entre as percepções dos estudantes durante vivências práticas dessas atividades, ao longo da disciplina específica sobre 0 assunto do curso de graduação, sendo consideradas imprescindíveis para o bom desempenho coletivo.

No que concerne aos valores/competência ética, que englobam a posse de valores pessoais e profissionais e a capacidade de fazer julgamentos adequados em relação às atividades de trabalho (CHEETHAM; CHIVERS, 1996, 1998), apresentam-se os resultados das percepções dos instrutores na Tabela 4. É possível constatar o domínio total dessas competências pela maioria dos instrutores, principalmente em referência à ética pessoal e à ética profissional.

Tabela 4 - Percepções de competências ética/valores por instrutores de atividades de aventura na natureza atuantes em Florianópolis/SC $(n=22)$.

\begin{tabular}{|c|c|c|c|}
\hline \multirow[b]{2}{*}{$\begin{array}{l}\text { Competência } \\
\text { nuclear }\end{array}$} & \multirow[b]{2}{*}{ Dimensões da competência (f) } & \multicolumn{2}{|c|}{ Percepção de competências } \\
\hline & & $\begin{array}{c}\text { Domina } \\
\text { parcialmente esta } \\
\text { competência (f) }\end{array}$ & $\begin{array}{c}\text { Domina totalmente esta } \\
\text { competência (f) }\end{array}$ \\
\hline \multirow{5}{*}{$\begin{array}{l}\text { Valores / } \\
\text { Competência } \\
\text { ética }\end{array}$} & Ética pessoal & 1 & 21 \\
\hline & $\begin{array}{l}\text { Ética profissional - código } \\
\text { profissional de conduta ética }\end{array}$ & 0 & 22 \\
\hline & Ética profissional - atualização & 4 & 18 \\
\hline & Sensibilização ambiental & 7 & 15 \\
\hline & Comprometimento socioambiental & 8 & 14 \\
\hline
\end{tabular}

Enquanto a ética pessoal inclui aspectos relacionados com o respeito pela lei, pelos códigos religiosos e morais, e a sensibilidade face aos valores e necessidades dos outros, a ética profissional inclui a adoção de atitudes adequadas, o cumprimento dos códigos de conduta profissional, 0 dever de se manter atualizado e de ajudar a trazer novos aportes para a profissão (BATISTA, 2008; CHEETHAM; CHIVERS, 1996, 1998). A percepção, por quatro 
instrutores, de dominar parcialmente a capacidade de se manter atualizado, buscando novos conhecimentos por meio de capacitações remete, novamente, ao estado da arte da formação desses profissionais, o qual, apresentando-se de forma difusa e variada, muitas vezes não alcança todos os que atuam nesse âmbito (ARAÚJO, 2012; AURICCHIO, 2013; SCHWARTZ; CARNICELLI FILHO, 2006).

No que se refere à capacidade de sensibilizar os participantes sobre as questões socioambientais, também é possível verificar que alguns instrutores dominam parcialmente esta competência. De acordo com Marinho (2008), as atividades de aventura na natureza parecem despertar atitudes hedonistas, cooperativas, sensibilizadoras, experimentações, entre outras possibilidades, envolvendo aquelas relativas ao ambiente natural. No entanto, a autora lembra que o contrário também pode ser verdadeiro quando se remete, por exemplo, a pacotes fechados de ecoturismo em que tudo é detalhadamente estruturado (horário das refeições, horário dos passeios, do ficar à toa, etc.), impedindo comportamentos e atitudes mais livres e flexíveis.

Dessa forma, a espontaneidade e a sensibilização com relação ao ambiente natural podem tanto ser despertadas nas pessoas a partir das atividades de aventura na natureza, como tolhidas e inibidas, considerando a forma com que o profissional instrui os participantes nessas vivências (MARINHO, 2008). Para Tahara e Carnicelli Filho (2009), os profissionais que atuam nessa área são decisivos para que as experiências pessoais e educativas estejam ao alcance de todos os participantes, devendo favorecer um aprendizado de valores, atitudes e condutas que possibilitem ao ser humano desfrutar dos prazeres, das emoções e dos riscos que as atividades de aventura na natureza podem oferecer. Dialoga-se com esses autores no sentido de incluir a sensibilização e o comprometimento ambiental nessas discussões, no sentido de os instrutores serem capazes de promover ações estimulando a prevenção dos impactos socioambientais.

No estudo de Chao et al. (2015), que comparou a avaliação do comportamento próambiental de idosos e de profissionais atuantes em atividades de aventura na natureza, os autores verificaram que estes últimos parecem contribuir mais para o desenvolvimento do comportamento pró-ambiental, tendo vista o fato de apresentarem tendências ecocêntricas com maior frequência, em detrimento das tendências antropocêntricas e da apatia ambiental. Os autores acreditam que a atividade profissional com atividades de aventura na natureza possibilita esse cunho educativo em relação ao ambiente, que é refletido pelas próprias atitudes de conservação e preservação do meio em que as atividades são desenvolvidas. Na presente pesquisa, entretanto, oito profissionais afirmaram dominar parcialmente a competência referente ao comprometimento ambiental, dando indícios de que, assim como no caso da sensibilização ambiental, talvez sejam necessários mais estímulos, capacitações específicas e experiências junto à natureza para o desenvolvimento do domínio total dessas competências.

Por fim, na Tabela 5, estão apresentados os resultados sobre os fatores relacionados à competência, referente às metacompetências (competências que transpassam outras, como a liderança, a motivação e a criatividade), à personalidade (características pessoais que influenciam o desempenho profissional), à reflexão (que age como um tipo de "ponteiro" para o desempenho de forma mais ampla), à avaliação da atuação (no sentido de identificar as causas de sucesso ou insucesso) e ao empreendedorismo (identificando novas oportunidades de atuação profissional) (ASSOCIAÇÃO BRASILEIRA DE NORMAS TÉCNICAS, 2005; 
CHEETHAM; CHIVERS, 1996, 1998). Novamente, a percepção de domínio total é evidente entre a maioria dos instrutores, mas devem ser mencionadas as seis percepções de domínio parcial da capacidade de avaliação e as cinco para a criatividade e a capacidade empreendedora, assim como a percepção de não domínio desta última por um instrutor.

Tabela 5 - Percepções de fatores relacionados à competência por instrutores de atividades de aventura na natureza atuantes em Florianópolis/SC $(n=22)$.

\begin{tabular}{lccc}
\hline & \multicolumn{3}{c}{ Percepção de competências } \\
\hline $\begin{array}{l}\text { Fatores relacionados à competência } \\
\text { (f) }\end{array}$ & $\begin{array}{c}\text { Não domina esta } \\
\text { competência (f) }\end{array}$ & $\begin{array}{c}\text { Domina parcialmente } \\
\text { esta competência (f) }\end{array}$ & $\begin{array}{c}\text { Domina totalmente } \\
\text { esta competência (f) }\end{array}$ \\
\hline Metacompetência - Liderança & 0 & 1 & 21 \\
\hline Metacompetência - Motivação & 0 & 2 & 20 \\
\hline Metacompetência - Criatividade & 0 & 5 & 17 \\
\hline Personalidade & 0 & 4 & 18 \\
\hline Reflexão & 0 & 4 & 18 \\
\hline Avaliação & 0 & 6 & 16 \\
\hline Empreendedorismo & 1 & 5 & 16 \\
\hline \multicolumn{4}{r}{ f: frequência simples. } \\
Fonte: Autoria própria (2016). & &
\end{tabular}

No que condiz à avaliação, Dodds (1994) enfatiza que o profissional competente possui sua autoconfiança elevada e tende a buscar novos conhecimentos, a fim de conquistar um domínio cada vez mais específico de sua profissão. Nesse sentido, é necessário que o instrutor de atividades de aventura na natureza realize uma avaliação constante de sua atuação, no intuito de verificar as causas de sucesso ou insucesso e, consequentemente, identificar quais pontos ele precisa melhorar e, assim, procurar mais conhecimentos nesses aspectos. No presente estudo, o fato de seis instrutores dominarem parcialmente a competência avaliação pode estar relacionado à falta de atualização dos conhecimentos com frequência ou à estagnação pela busca de melhoria.

Sobre a criatividade, Bruhns e Marinho (2011) acreditam que essa competência está diretamente relacionada à sensibilidade, uma vez que esta última pode ser convertida em criatividade ao ligar-se com uma atividade social significativa para o indivíduo. Nesse sentido, as autoras explicam que alguns traços de personalidade podem ser estimulados para o melhor aproveitamento do potencial criativo, tais como: a autonomia; a flexibilidade pessoal e a abertura à experiência, relacionadas à tolerância, à ambiguidade e à habilidade em receber informações conflitantes; a autoconfiança, iniciativa e persistência, incentivando o indivíduo a correr os riscos a fim de ultrapassar seus conhecimentos e persistir nos objetivos almejados; e a sensibilidade emocional, subvertendo a ideia de a criatividade estar somente vinculada às regras da lógica.

Por fim, em relação ao empreendedorismo, competência que pode, inclusive, alavancar a área da aventura, com vistas à identificação de novas oportunidades de atuação profissional, Dumont (2016) apresenta uma proposta realizada por instrutores de alpinismo, os quais, concomitantemente à atuação com essa atividade, apropriam-se de diversos aparatos tecnológicos virtuais a fim de disseminar suas próprias atividades e de expandir-se no mercado de trabalho. Com base nestas informações, reforça-se a importância de estar 
atento às novidades no entorno profissional, pois aumentam as chances de alcançar mercados ainda não explorados ou potencializar/melhorar o trabalho realizado. A avaliação constante, a criatividade e o empreendedorismo mostram-se como competências ainda latentes na atuação de alguns instrutores de atividades de aventura na natureza em Florianópolis/SC.

\section{CONCLUSÕES}

Diante dos resultados apresentados, fica evidente que os instrutores de atividades de aventura investigados se percebem totalmente competentes na maioria dos itens analisados, sendo que, vez ou outra, sentem-se parcialmente competentes e, em raros casos, percebem não dominar determinadas competências. Isso demonstra que, mesmo com a inexistência de uma formação específica, os instrutores investigados, em seus diversos percursos profissionais, encontraram a possibilidade de desenvolver as mais diferentes competências aqui estudadas, de acordo com sua percepção.

Levando em consideração a subjetividade intrínseca aos estudos que envolvem as competências, este estudo, para além de contribuir com a análise da percepção de competências profissionais de instrutores de atividades de aventura na natureza, pode servir como um caminho para novas reflexões acerca dos conteúdos a serem trabalhados nas capacitações que envolvem esses profissionais e nos cursos de formação inicial em Educação Física. Nesta direção, os indivíduos atuantes com essas atividades poderiam desenvolver as mais diversas competências e fatores relacionados a elas, com vistas a oferecer um atendimento cada vez mais qualificado e significativo aos participantes. Sugere-se, portanto, a realização de estudos similares a este em outras cidades brasileiras, contribuindo para o entendimento e para as discussões sobre as competências percebidas por instrutores de atividades de aventura na natureza.

\section{REFERÊNCIAS}

ASSOCIAÇÃO BRASILEIRA DE NORMAS TÉCNICAS. NBR 15285: esporte de aventura - condutores - competência de pessoal. Rio de Janeiro, 2005. Disponível em: < http://www.sistemafaemg.org. br/agenteturismo/Legisla\%C3\%A7\%C3\%A30\%20do\%20Agente\%20de\%20Turismo\%20Rural/ NBR/15285-competencias-de-pessoal.pdf >. Acesso em: 20 nov. 2015.

ARAÚJO, Jeyller Henrique Rosa. A formação de profissionais que atuam com esportes e atividades de lazer na natureza no entorno da cidade de Belo Horizonte/MG. 2012. $132 \mathrm{f}$. Dissertação (Mestrado em Lazer) - Escola de Educação Física, Fisioterapia e Terapia Ocupacional, Universidade Federal de Minas Gerais, Belo Horizonte, 2012.

AURICCHIO, José Ricardo. Formação e atuação profissional em atividade de aventura no âmbito do lazer. 2013. 183 f. Dissertação (Mestrado em Educação Física) - Faculdade de Ciências da Saúde, Universidade Metodista de Piracicaba, Piracicaba, 2013.

BATISTA, Paula Maria Fazendeiro. Discurso sobre a competência: contributo para a (re)construção de um conceito de competência aplicável ao profissional do desporto. 2008. 591 f. Dissertação (Doutorado em Ciências do Desporto) - Faculdade de Desporto, Universidade do Porto, Porto, 2008. 
BATISTA, Paula Maria Fazendeiro; GRAÇA, Amândio Braga dos Santos; MATOS, Zélia. Competencia: entre significado y concepto. Revista de Educación, v. 10, p. 7-28, 2007. Disponível em: $<$ https://www.researchgate.net/publication/28222146 Competencia entre significado y concepto>. Acesso em: 17 maio 2016.

BETRÁN, Javier Olivera. BETRÁN, Alberto Olivera. Proposta pedagógica para as atividades físicas de aventura na natureza (AFAN) na Educação Física do ensino médio. In: MARINHO, Alcyane; BRUHNS, Heloísa Turini (Orgs.). Viagens, lazer e esporte: 0 espaço da natureza. Barueri: Manole, 2006. p. 180-210.

BRASIL. Ministério da Educação. Base Nacional Comum Curricular. 2. versão revista. Brasil, 2016. Disponível em: <http://basenacionalcomum.mec.gov.br/documentos/bncc-2versao.revista.pdf>. Acesso em: 2 nov. 2016.

BROWN, Mike; FRASER, Deborah. Re-evaluating risk and exploring educational alternatives. Journal of Adventure Education and Outdoor Learning, Buckinghamshire, v. 9, n. 1, p. 61-77, jun. 2009.

BRUHNS, Heloísa Turini; MARINHO, Alcyane. Criatividade: a exceção essencial. Revista Brasileira de Ciências e Movimento, v. 19, n. 4, p. 97-107, abr./jun. 2011.

$\mathrm{CHAO}$, Cheng Hsin Nery et al. Atividades de aventura na natureza e desenvolvimento do comportamento pró-ambiental: análise comparativa entre idosos e condutores. Movimento, v. 21, n. 1, p. 169-180, jan./mar. 2015.

CHEETHAM, Graham; CHIVERS, Geoff. Towards a holistic model of professional competence. Journal of European Industrial Training, v. 20, n. 5, p. 20-30, 1996.

CHEETHAM, Graham; CHIVERS, Geoff. The reflective (and competent) practitioner: A model of professional competence which seeks to harmonize the reflective practitioner and competence-based approaches. Journal of European Industrial Training, v. 22, n. 6/7, p. 267-276, 1998.

DAL PUPO, Juliano; SCHUTZ, Gustavo Ricardo; SANTOS, Saray Giovana. Instrumentos de medida. In: SANTOS, Saray Giovana (Org.). Métodos e técnicas de pesquisa quantitativa aplicada à Educação Física. Florianópolis: Tribo da llha, 2011. p. 141-190.

DODDS, Patt. Cognitive and behavioral components of expertise in teaching Physical Education. Quest, v. 46, n. 2, 153-163, may 1994.

DUMONT, Guillaume. Multi-layered labor: entrepreneurship and professional versatility in rock climbing. Ethnography, v. 17, n. 1, p. 77-86, mar. 2016.

FARIAS, Gelcemar Oliveira. Carreira docente em Educação Física: uma abordagem na construção da trajetória profissional do professor. 2010. 303 f. Tese (Doutorado em Educação Física) - Centro de Desportos, Universidade Federal de Santa Catarina, Florianópolis, 2010.

FARIAS, Gelcemar Oliveira et al. Competências profissionais em Educação Física: uma abordagem ao longo da carreira docente. Motriz, v. 18, n. 4, p. 656-666, out./dez. 2012.

GIL, Antônio Carlos. Métodos e técnicas de pesquisa social. 6. ed. São Paulo: Atlas, 2008.

HIGINS, Peter; HUMBERSTONE, Barbara. Introduction. In: HIGINS, Peter; HUMBERSTONE, Barbara. (Ed.). Outdoor education and experiential learning in the UK. Verlag ErlebnispadagogikLuneburg: Germany, 1999. p. 5-7. Disponível em: <http://files.eric.ed.gov/fulltext/ED471720.pdf>. Acesso em: 9 jun. 2016. 
INÁCIO, Humberto Luís de Deus et al. Práticas corporais de aventura na escola: possibilidades e desafios - reflexões para além da Base Nacional Comum Curricular. Motrivivência, v. 28, n. 48, p. 168-187, set. 2016.

INÁCIO, Humberto Luís de Deus; MORAES, Thais Messias; SILVEIRA, Amanda Batista de. Educação física e educação ambiental: refletindo sobre a formação e atuação docente. Conexões, v. 11, n. 4, p. 1-23, out./dez. 2013.

MARCONI, Marina de Andrade; LAKATOS, Eva Maria.Técnicas de pesquisa: planejamento e execução de pesquisas, amostragens e técnicas de pesquisa, elaboração, análise e interpretação dos dados. 7. ed. São Paulo: Atlas, 2009.

MARINHO, Alcyane. Atividades na natureza, lazer e educação ambiental: refletindo sobre algumas possibilidades. Motrivivência, v. 16, n. 22, p. 47-70, jun. 2004.

MARINHO, Alcyane. Lazer, aventura e risco: reflexões sobre atividades realizadas na natureza. Movimento, v. 14, n. 2, p. 181-206, maio/ago. 2008.

MARINHO, Alcyane; SANTOS, Priscila Mari; MANFROI, Miraíra Noal; FIGUEIREDO, Juliana de Paula; BRASIL, Vinicius Zeilmann. Reflections about outdoor adventure sports and professional competencies of physical education students. Journal of Adventure Education and Outdoor Learning, v. 16, n. 1, p. 1-17, sep. 2016.

PAIXÃO, Jairo Antônio et al. Risco e aventura no esporte na percepção do instrutor. Psicologia \& Sociedade, v. 23, n. 2, p. 415-425, maio/ago. 2011.

PAIXÃO, Jairo Antônio; TUCHER, Guilherme. Risco e aventura por entre as montanhas de Minas: a formação do profissional de esporte de aventura. Pensar a prática, v. 13, n. 3, p. 1-19, set./dez. 2010.

SANTOS, Priscila Mari et al. Formação profissional e percepção de competências de estudantes de educação física: uma reflexão a partir da disciplina de esportes de aventura e na natureza. Revista da Educação Física/UEM, v. 26, n. 4, p. 529-540, 4. trim. 2015.

SANTOS, Saray Giovana; GHELLER, Rodrigo Ghedini. Construção e validação de instrumentos para coleta. In: SANTOS, S. G. (Org.) Métodos e técnicas de pesquisa qualitativa aplicada à Educação Física. Florianópolis: Tribo da llha, 2012. p. 195-206.

SCHWARTZ, Gisele Maria; CARNICELLI FILHO, Sandro. (Desin)Formação profissional e atividades de aventura: focalizando os guias de "Rafting". Revista Brasileira de Educação Física e Esportes, v. 20, n. 2, p. 103-09, abr./jun. 2006.

SORIANO, Jeane Barcelos; WINTERSTEIN, Pedro José. Limites e desafios para o estudo da intervenção profissional em Educação Física a partir da noção de competência. Movimento, v. 12, n. 1, p. 175-195, jan./abr. 2006.

TAHARA, Alexander; CARNICELLI FILHO, Sandro. Atividades físicas de aventura na natureza (AFAN) e academias de ginástica: motivos de aderência e benefícios advindos da prática. Movimento, v. 15, n. 3, p. 187-208, jul./set. 2009. 